\title{
Interhospital transfer of pediatric neurosurgical patients
}

\author{
Aditya Vedantam, MD, ${ }^{1}$ Daniel Hansen, MD, ${ }^{1}$ Valentina Briceño, RN, ${ }^{1}$ Amee Moreno, NP, ${ }^{1}$ \\ Sheila L. Ryan, MPH, JD, ${ }^{1}$ and Andrew Jea, MD'1-3
}

\begin{abstract}
1Division of Pediatric Neurosurgery, Texas Children's Hospital, Department of Neurosurgery, Baylor College of Medicine, Houston, Texas; ${ }^{2}$ Section of Pediatric Neurosurgery, Riley Hospital for Children, Department of Neurosurgery, Indiana University School of Medicine; and ${ }^{3}$ Goodman Campbell Brain and Spine, Indianapolis, Indiana
\end{abstract}

\begin{abstract}
OBJECTIVE The purpose of this study was to describe patterns of transfer, resource utilization, and clinical outcomes associated with the interhospital transfer of pediatric neurosurgical patients.

METHODS All consecutive, prospectively collected requests for interhospital patient transfer to the pediatric neurosurgical service at Texas Children's Hospital were retrospectively analyzed from October 2013 to September 2014. Demographic patient information, resource utilization, and outcomes were recorded and compared across predefined strata (low $[<5 \%]$, moderate [5\%-30\%], and high [> 30\%]) of predicted probability of mortality using the Pediatric Risk of Mortality score.
\end{abstract}

RESULTS Requests for pediatric neurosurgical care comprised 400 (3.7\%) of a total of 10,833 calls. Of 400 transfer admissions, $96.5 \%, 2.8 \%$, and $0.8 \%$ were in the low, moderate, and high mortality risk groups, respectively. The median age was 54 months, and $45 \%$ were female. The median transit time was 125 minutes. The majority of transfers were after-hours (69.8\%); nearly a third occurred during the weekend (32.3\%). The median intensive care unit stay for 103 patients was 3 days (range 1-269 days). Median length of hospital stay was 2 days (range 1-269 days). Ninety patients $(22.5 \%)$ were discharged from the emergency room after transfer. Seventy-seven patients $(19.3 \%)$ required neurosurgical intervention after transfer, with the majority requiring a cranial procedure $(66.2 \%) ; 87.3 \%$ of patients were discharged home.

CONCLUSIONS This study highlights patient characteristics, resource utilization, and outcomes among pediatric neurosurgical patients. Opportunities for quality improvement were identified in diagnosing and managing isolated skull fractures and neck pain after trauma.

http://thejns.org/doi/abs/10.3171/2016.5.PEDS16155

KEY WORDS interhospital transfer; health resources; trauma; outcome assessment

$\mathrm{N}$ EUROSURGICAL care may be a common reason for interhospital transfer. , $21,36,37$ The impetus to transfer children for specialized pediatric services is no different. ${ }^{9,34}$ The primary indication for transfer is the need for urgent or emergency neurosurgical evaluation and intervention. Often, transferred patients have acute lifethreatening conditions such as intracranial hemorrhage or hydrocephalus. Many hospitals lack full-time neurosurgical coverage, ${ }^{21,28}$ and the demand for interhospital transfer will increase as surgical subspecialists consolidate into larger regional pediatric surgical centers of excellence as designated by the American College of Surgeons. ${ }^{32}$

Previous studies ${ }^{9,34}$ of the transfer of critically ill children in the general pediatric patient population have demonstrated significant differences in patient characteristics, resource utilization, and outcomes across mortality risk- stratified groups. Costly length of intensive care unit (ICU) stay and incidence of invasive procedures were greater in the high-risk admissions, as compared with the low- and moderate-risk admissions. In addition, these same studies $^{9,34}$ showed a higher mortality rate in the high-risk admissions, compared with low- and moderate-risk admissions.

To the best of our knowledge, the criteria for the transfer of pediatric neurosurgical patients, the resource utilization involved, and the characteristics of transferred patients have not been previously studied. Furthermore, there is a lack of data regarding outcomes for pediatric neurosurgical patients who undergo transfer. Our study aimed to examine the characteristics, resource utilization, and outcomes of transfer admissions to the pediatric neurosurgical service at a large tertiary/quaternary children's hospital. 


\section{Methods}

\section{Study Population}

All consecutive prospectively documented requests for interhospital patient transfer to the pediatric neurosurgical service at Texas Children's Hospital from October 1, 2013, to September 30, 2014, were retrospectively identified from a centralized transfer center database. Texas Children's Hospital is a 495-bed freestanding children's hospital, which attained Level I trauma designation in October 2010. The local Institutional Review Board approved this study with a waiver of informed consent.

\section{Data Collection}

Details of each patient transfer request were extracted from the transfer center database, including time of transfer request, duration of transit, time of arrival at our institution, reason for transfer, and reported diagnosis at the time of transfer request. The distance traveled for transfer was calculated using the shortest distance between the referring facility and our hospital on Google Maps. Electronic medical records of these patients were then reviewed for diagnostic, laboratory, physiological, and demographic information collected on all patients within 24 hours of admission. Therapeutic interventions, duration of use, and length of overall hospital stay and ICU stay were noted. Data on clinical outcomes were also collected at the time of discharge.

\section{Pediatric Risk of Mortality}

The Pediatric Risk of Mortality (PRISM) score was developed to assess pediatric ICU and surgical risk of mortality. ${ }^{25}$ Data for computation of the PRISM score were obtained within the first 24 hours of admission, and the PRISM score was calculated using the formula published by Pollack et al. ${ }^{28}$

\section{Analysis of Resource Utilization}

Resource utilization was assessed using information regarding receipt of neurosurgical procedures, length of stay in the ICU, and duration of hospital stay. Clinical outcomes were analyzed, including hospital and ICU length of stay and survival status at hospital discharge. For survivors, the discharge destination was determined, including home, rehabilitation, hospice, long-term skilled nursing facility, or transfer back to the referring hospital.

\section{Data Analysis}

Descriptive statistics, including means, standard deviations, standard errors, and confidence intervals, were computed as necessary. Bivariate analyses compared patient characteristics, resource utilization, and outcomes across predefined strata (low $[<5 \%]$, moderate [5\%-30\%], and high $[>30 \%])$ of predicted probability of mortality using the PRISM algorithm. ${ }^{25}$ Bivariate comparisons of categorical and nonparametric continuous data across the 3 mortality risk strata were performed using the chi-square and Kruskal-Wallis tests, respectively. Analysis was performed using SPSS statistical package (version 21, IBM Corp.). All p values $<0.05$ were considered significant.

\section{Results \\ Patient Transfer Requests}

There were a total of 10,833 requests for transfer of pediatric patients during the study period. Requests for transfer to the pediatric neurosurgical service constituted $400(3.7 \%)$ of the total requests. The majority of the transfers were via ground transport (85.8\%; Table 1). Air transport (helicopter or airplane) was used in $14.2 \%$ of cases. Transfers from our affiliated West Campus, approximately 25 miles away, accounted for $17.5 \%$ of the transfers. Overall, there were 118 unique referring facilities for the study group. The median driving distance between the referring facility and our hospital was 37.7 miles (range 0.2-750 miles).

The overall median transit time (i.e., time interval between accepting the transfer and arrival of the transfer) was 125 minutes for pediatric neurosurgical transfers. However, the overall median time interval between receiving the transfer request and patient arrival was 139.5 minutes. This time interval includes the time required for the physician to review the transfer request and communicate acceptance to the referring facility. The majority of transfers $(69.8 \%$, Fig. 1 upper) were admitted to our facility after-hours (from 6 PM to $6 \mathrm{AM})$, and nearly a third of the transfers were admitted on the weekend (32.3\%, Fig. 1 lower).

\section{Patient Characteristics}

Of 400 transfer admissions, $96.5 \%, 2.8 \%$, and $0.8 \%$

TABLE 1. Patient demographics and transfer characteristics for patients transferred for pediatric neurosurgical evaluation

\begin{tabular}{|c|c|c|}
\hline Variable & No. of Patients & $\%$ \\
\hline \multicolumn{3}{|l|}{ Age (yrs) } \\
\hline$<1$ & 104 & 26 \\
\hline $1-6$ & 134 & 33.5 \\
\hline $6-12$ & 79 & 19.8 \\
\hline $12-18$ & 79 & 19.8 \\
\hline$>18$ & 4 & 1 \\
\hline \multicolumn{3}{|l|}{ Sex } \\
\hline Male & 220 & 55 \\
\hline Female & 180 & 45 \\
\hline \multicolumn{3}{|c|}{ Mortality risk cohorts } \\
\hline Low & 386 & 96.5 \\
\hline Moderate & 11 & 2.8 \\
\hline High & 3 & 0.8 \\
\hline \multicolumn{3}{|c|}{ Method of transport } \\
\hline Ambulance & 340 & 85 \\
\hline Private car & 3 & 0.8 \\
\hline Helicopter & 56 & 14 \\
\hline Plane & 1 & 0.3 \\
\hline \multicolumn{3}{|c|}{ Transit time (mins) } \\
\hline$<60$ & 115 & 28.7 \\
\hline $60-120$ & 77 & 19.3 \\
\hline $120-180$ & 80 & 20 \\
\hline $180-240$ & 56 & 14 \\
\hline$>240$ & 72 & 18 \\
\hline
\end{tabular}



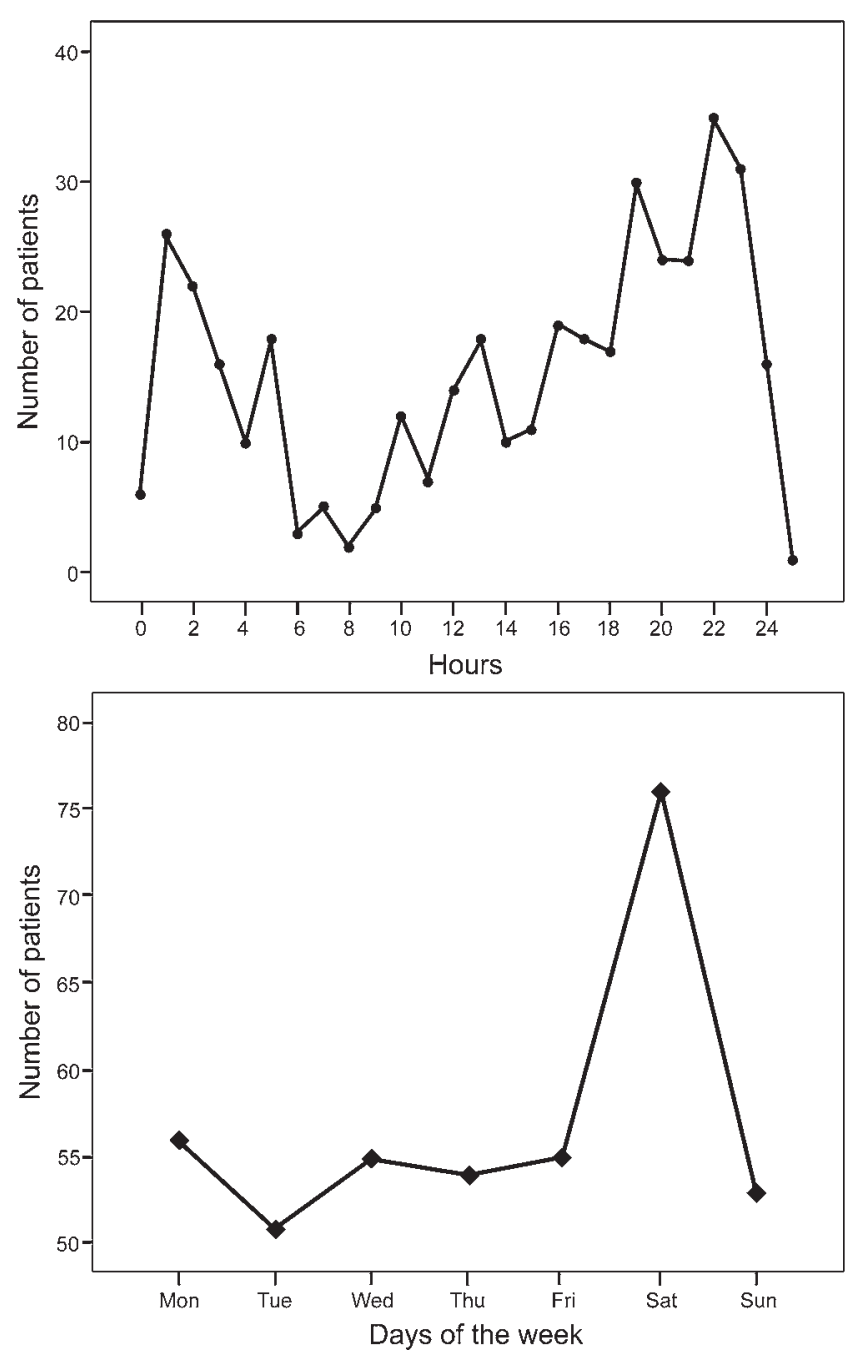

FIG. 1. Graphs of time of admission (upper) and day of admission (lower) for pediatric patients transferred for neurosurgical evaluation.

were in the low, moderate, and high mortality risk cohorts, respectively. The median patient age was 54 months (range $0.4-264$ months), and $45 \%$ of the study population was female (Table 1). Demographic data were similar among the different mortality risk groups (Table 2). The most frequent diagnoses at the time of request for transfer were skull fracture (24.8\%), subdural hematoma (8\%), and head injury (5.8\%). Traumatic brain injury, with or without intracranial hemorrhage, was the most common actual diagnosis for transferred patients (Fig. 2). Isolated skull fracture, noted in 84 patients (21\%), was the most common single diagnosis at discharge. Incorrect diagnoses were noted in 35 patients. The most common transfer request with an incorrect diagnosis was spine fracture. Five patients were transferred with the diagnosis of spine fracture but had a negative clinical and radiographic workup at our facility.

\section{Resource Utilization}

One hundred three patients were admitted to the ICU after transfer, with a median of 3 days (range 1-269 days) spent in the ICU. The mean length of stay in the hospital
TABLE 2. Patient demographics, resource utilization, and outcomes based on predicted mortality risk calculated from the PRISM score

\begin{tabular}{|c|c|c|c|c|}
\hline \multirow[b]{2}{*}{ Variable } & \multicolumn{3}{|c|}{ Predicted Mortality Risk } & \multirow[b]{2}{*}{ p Value } \\
\hline & $<5 \%$ & $5 \%-30 \%$ & $>30 \%$ & \\
\hline No. of patients & 386 & 11 & 3 & \\
\hline Median age (yrs) & 5.5 & 1.9 & 2 & 0.11 \\
\hline$\%$ females & 44.8 & 45.5 & 66.7 & 0.75 \\
\hline Median transit time (mins) & 129 & 131 & 109 & 0.92 \\
\hline Median total transfer time (mins) & 155 & 144 & 131 & 0.91 \\
\hline Neurosurgery (yes) & 71 & 5 & 1 & 0.06 \\
\hline $\begin{array}{l}\text { Median length of stay in hospital } \\
\text { (days) }\end{array}$ & 8 & 5.5 & 2 & 0.001 \\
\hline Median length of ICU stay (days) & 2 & 5.5 & 2 & 0.12 \\
\hline \multicolumn{5}{|l|}{ Actual diagnosis } \\
\hline VPS/HCP & 22 & 0 & 0 & \\
\hline Tumor & 30 & 0 & 0 & \\
\hline Traumatic brain injury & 219 & 6 & 2 & \\
\hline Vascular & 15 & 0 & 0 & \\
\hline Infection & 5 & 0 & 0 & \\
\hline Spinal & 40 & 1 & 0 & \\
\hline Seizures/AMS/vomiting & 35 & 0 & 0 & \\
\hline Other & 20 & 4 & 1 & \\
\hline \multicolumn{5}{|l|}{ Disposition } \\
\hline Home & 345 & 3 & 1 & \\
\hline CPS & 18 & 3 & 0 & \\
\hline Rehabilitation facility & 18 & 1 & 0 & \\
\hline Hospice & 3 & 0 & 0 & \\
\hline Transfer to another hospital & 0 & 2 & 0 & \\
\hline Death & 2 & 2 & 2 & \\
\hline
\end{tabular}

AMS = altered mental status; $\mathrm{CPS}=$ child protective services; $\mathrm{VPS} / \mathrm{HCP}=$ ventriculoperitoneal shunt/hydrocephalus.

was 2 days (range 1-269 days) for 400 patients. Ninety patients $(22.5 \%)$ were discharged directly from the emergency room after transfer. Most of these discharges-ontransfer had a diagnosis of isolated skull fracture (53.3\%). Seventy-seven patients (19.3\%) required neurosurgical intervention after transfer, with the majority requiring a cranial procedure (66.2\%). The types of surgical procedures performed are shown in Table 3.

\section{Outcomes}

Table 3 describes the discharge disposition for patients in this study. The majority of patients were discharged home $(87.3 \%)$. Six patients $(1.5 \%)$ died in the entire study population. Four patients deemed low- or moderate-risk at the time of transfer died for the following reasons: $\mathrm{C} 1-2$ dislocation with traumatic brain injury, cerebellar hemorrhage, hydrocephalus with sepsis, and brain tumor with hydrocephalus.

\section{Discussion}

In this first study to describe interhospital transfer of 


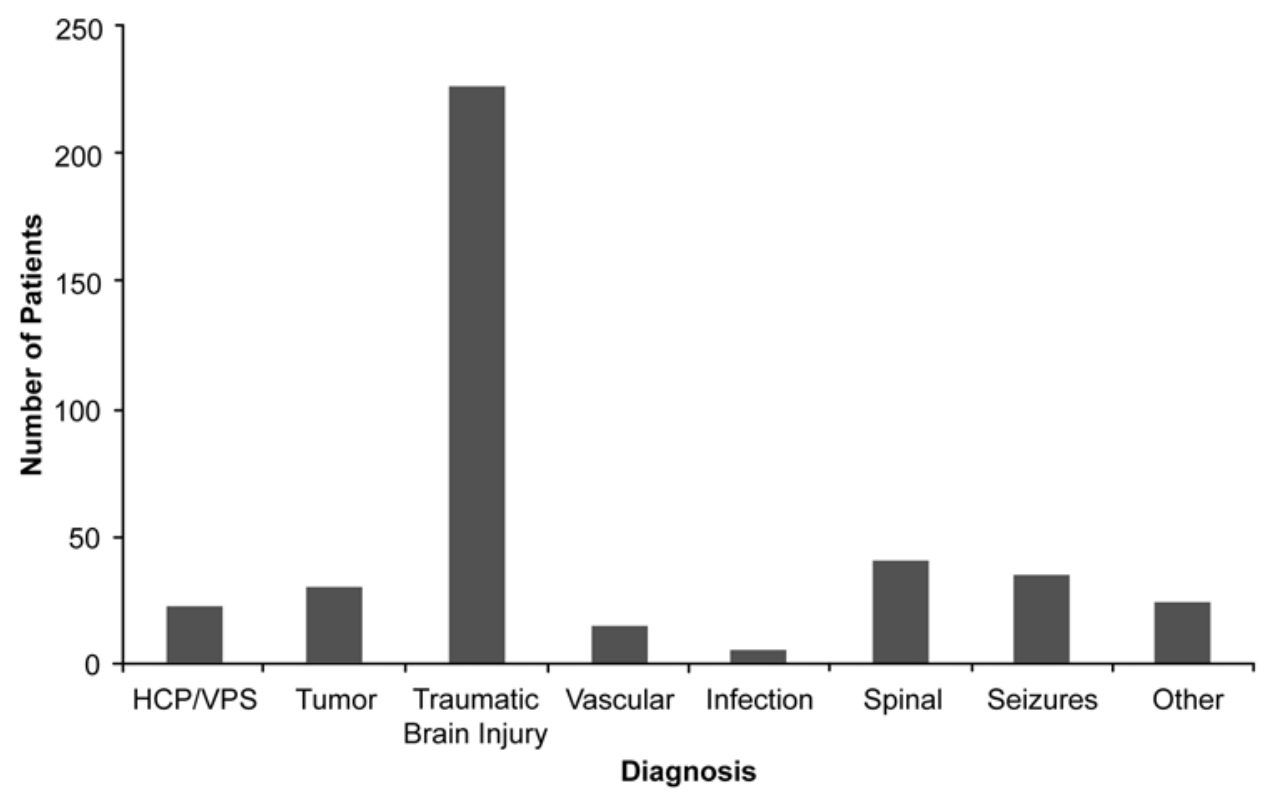

FIG. 2. Bar graph showing actual diagnosis categories for 400 pediatric patients transferred for neurosurgical evaluation. $\mathrm{HCP}=$ hydrocephalus; VPS = ventriculoperitoneal shunt.

pediatric neurosurgical patients, reasons for transfer, hospital course, and discharge disposition have been described for a large tertiary/quaternary children's hospital over the course of 12 months. Pediatric neurosurgical transfers were relatively uncommon at our facility, comprising only $3.7 \%$ of all transfer requests. Nonetheless, the absence of neurosurgical coverage is a common indication for interhospital transfer. ${ }^{21}$ Many outlying community hospitals do not have pediatric neurosurgeons on staff, whereas others

TABLE 3. Resource utilization and outcomes of care for 400 patients transferred for neurosurgical evaluation

\begin{tabular}{lcc}
\hline \multicolumn{1}{c}{ Variable } & No. of Patients & $\%$ \\
\hline Neurosurgical intervention & & \\
\hline$\quad$ Craniotomy for tumor & 24 & 6.0 \\
\hline Craniotomy for hematoma* & 19 & 4.8 \\
\hline $\begin{array}{l}\text { Ventriculoperitoneal shunt insertion or } \\
\text { revision }\end{array}$ & 12 & 3.0 \\
\hline Spine surgery & 11 & 2.8 \\
\hline Ventricular drain/tap & 7 & 1.8 \\
\hline Others† & 4 & 1.1 \\
\hline Median length of hospital stay in days (range) & $2(1-269)$ & - \\
\hline Median length of ICU stay in days (range) & $3(1-269)$ & - \\
\hline Disposition & & \\
\hline Home & 349 & 87.3 \\
\hline CPS & 21 & 5.3 \\
\hline Rehabilitation facility & 19 & 4.8 \\
\hline Hospice & 3 & 0.8 \\
\hline Transfer to another hospital & 2 & 0.5 \\
\hline Death & 6 & 1.5 \\
\hline
\end{tabular}

* Includes cranioplasty.

$\dagger$ Includes vagus nerve stimulation $(n=2)$, transsphenoidal resection $(n=1)$, baclofen pump revision $(n=1)$. do not provide full-time pediatric neurosurgical coverage. The American College of Surgeons has recognized that higher-volume pediatric surgical centers may achieve better outcomes. ${ }^{32}$ Furthermore, other data indicate that highvolume centers may achieve better outcomes for certain neurosurgical conditions, ${ }^{13}$ which has further stimulated regionalization of care and the trend toward transfer of patients to specialized centers. ${ }^{6,14,22,24}$ The management of some pediatric neurosurgical conditions requires dedicated teams, such as neurointensivists, that may not be available at other facilities; in the adult neurosurgical patient population, this has been shown to improve outcomes. ${ }^{2,13}$ Patients or family members may request transfers on the basis of outside recommendations or the reputation of a particular center. ${ }^{21}$ Unfortunately, there are other reasons for transfer, such as concerns over professional liability or a patient's insurance status. On the basis of recent trends in the delivery of health care sparked by national health care reform, including hospital system consolidation, subspecialization, and regionalization, ${ }^{5}$ we expect that interhospital transfers in pediatric neurosurgery will become increasingly more common.

\section{Opportunities for Quality Improvement}

Telemedicine-and in particular teleradiology-technology has existed for quite a long period of time. ${ }^{8}$ However, its implementation in the interhospital transfer process has not been consistently applied. Prior research has shown that teleradiology increased the intervention rate in transferred patients, decreased transfer time, reduced unnecessary transfers, and even reduced the number of adverse events during transfer itself. ${ }^{1}$ Specifically, patients with isolated skull fractures, and those with isolated neck pain without evidence of fractures on CT imaging, may be examined remotely by the neurosurgeon using an audiovideo interface. Isolated skull fractures without evidence of intracranial hemorrhage, which composed the majority 
of patients discharged from our emergency room soon after transfer (53.3\%), is a relatively benign diagnosis given the low likelihood for neurological deterioration or intervention. ${ }^{3,29,30}$ The presence of neck pain without neurological deficits and a normal CT scan of the neck, in an older child, is another condition in which a clinical decision rule for transfer should be used. The neurosurgeon would be more confident of the patient's clinical examination and could potentially avoid transferring those patients who would be discharged home from the emergency room after transfer. In the present study, although we could review radiological images from our affiliate hospital (17.5\% of transfers), we could not clinically evaluate the patient, and this limited our ability to reduce unnecessary transfers. In addition to the introduction of telemedicine, the implementation of frequent educational workshops on common neurosurgical conditions for emergency room teams, as well as general pediatricians at major community hospitals, is needed. The creation and distribution of well-defined clinical protocols for common neurosurgical cases among our referring centers is essential to change transfer practices.

This study also highlighted the large number of patients arriving after-hours or on the weekends. A proportion of these transfers may be attributed to working parents unable to take their children to the hospital during regular working hours on weekdays. However, delays in establishing a diagnosis and initiating a transfer request at the referring facility also contribute to these patterns. The potential impact of transfer delays is underscored by several studies reporting that pediatric patients who undergo surgery at night or on the weekend have higher complications rates, $3,7,10-12,15-20,23,26,29,31,33,35,38,39$ including an analysis of our own practice patterns in pediatric neurosurgery. ${ }^{30}$ Our results indicate the need for early transfer requests to reduce delays in care and after-hour transfers.

\section{PRISM in Pediatric Neurosurgery}

We stratified our study population into groups of predicted mortality based on PRISM score. These scores and their associated strata of risk were not associated with a shorter or longer transit time, expedited or prolonged ICU stay, or absence or need for neurosurgical intervention. Hence, the PRISM score may not be as valuable for pediatric neurosurgical patients undergoing interhospital transfer as it is for children cared for by other pediatric subspecialists. The use of the updated PRISM III score, which has revised the list of variables and ranges, may have improved the mortality prediction in our patient population. ${ }^{27} \mathrm{How}-$ ever, many of the neurosurgical patients did not have significant systemic physiological derangements at the time of transfer. These measures of systemic physiological variables, such as blood pressure, heart rate, respiratory rate, partial pressure of oxygen, and partial pressure of carbon dioxide, prothrombin time/partial thromboplastin time, total bilirubin, and serum electrolytes, are required by the PRISM formula.

\section{Limitations of the Study}

Certain limitations of this study need to be highlighted. Our study involved only 1 academic children's medical center; therefore, the results may not be generalizable to other children's hospitals in the US. Moreover, the case mix of patients and illness severity noted in our study population may not reflect those at other children's hospitals. Neurosurgery does not exist in isolation, and children with multisystem injury, who often require neurosurgical evaluation in addition to input from other services, will need to be transferred to a higher level of care. Many of these patients are brought directly to our facility by emergency services, and this may be the reason why the high mortality risk group was particularly small in our study.

In addition, we were unable to show that resource utilization varied according to the severity of illness of the patients. That is, greater risk of mortality was associated with higher utilization of resources. Unfortunately, only 3 high-risk patients were included in our study cohort, which limits meaningful comparisons between low-, moderate-, and high-risk groups. However, our methodological approach of describing the study cohort across strata of predicted mortality risk could be easily applied to other children's hospitals in the setting of future multicenter collaborations.

\section{Conclusions}

An appropriate and timely transfer process may improve care and safety for pediatric neurosurgical patients. This study serves as a first step in the identification and characterization of pediatric neurosurgical patients at the time of interhospital transfer. Future larger multiinstitutional studies based on our present work may demonstrate that resource consumption needs vary from primarily rehabilitative for lower-risk admissions, to aggressive surgical interventions for high-risk admissions. Multiple aspects of the transfer process of pediatric neurosurgical patients may be improved upon.

\section{References}

1. Anderson RC, Scaife ER, Fenton SJ, Kan P, Hansen KW, Brockmeyer DL: Cervical spine clearance after trauma in children. J Neurosurg 105 (5 Suppl):361-364, 2006

2. Arias Y, Taylor DS, Marcin JP: Association between evening admissions and higher mortality rates in the pediatric intensive care unit. Pediatrics 113:e530-e534, 2004

3. Arrey EN, Kerr ML, Fletcher S, Cox CS Jr, Sandberg DI: Linear nondisplaced skull fractures in children: who should be observed or admitted? J Neurosurg Pediatr 16:703-708, 2015

4. Babu MA, Nahed BV, Demoya MA, Curry WT: Is trauma transfer influenced by factors other than medical need? An examination of insurance status and transfer in patients with mild head injury. Neurosurgery 69:659-667, 2011

5. Barnett MJ, Kaboli PJ, Sirio CA, Rosenthal GE: Day of the week of intensive care admission and patient outcomes: a multisite regional evaluation. Med Care 40:530-539, 2002

6. Bershad EM, Feen ES, Hernandez OH, Suri MF, Suarez JI: Impact of a specialized neurointensive care team on outcomes of critically ill acute ischemic stroke patients. Neurocrit Care 9:287-292, 2008

7. Buckley D, Bulger D: Trends and weekly and seasonal cycles in the rate of errors in the clinical management of hospitalized patients. Chronobiol Int 29:947-954, 2012

8. Burke BL Jr, Hall RW: Telemedicine: pediatric applications. Pediatrics 136:e293-e308, 2015 
9. Byrne RW, Bagan BT, Slavin KV, Curry D, Koski TR, Origitano TC: Neurosurgical emergency transfers to academic centers in Cook County: a prospective multicenter study. Neurosurgery 62:709-716, 2008

10. Chang GM, Tung YC: Factors associated with pneumonia outcomes: a nationwide population-based study over the 1997-2008 period. J Gen Intern Med 27:527-533, 2012

11. Concha OP, Gallego B, Hillman K, Delaney GP, Coiera E: Do variations in hospital mortality patterns after weekend admission reflect reduced quality of care or different patient cohorts? A population-based study. BMJ Qual Saf 23:215222, 2014

12. Cram P, Hillis SL, Barnett M, Rosenthal GE: Effects of weekend admission and hospital teaching status on in-hospital mortality. Am J Med 117:151-157, 2004

13. Cross DT III, Tirschwell DL, Clark MA, Tuden D, Derdeyn CP, Moran CJ, et al: Mortality rates after subarachnoid hemorrhage: variations according to hospital case volume in 18 states. J Neurosurg 99:810-817, 2003

14. Cutler DM, Scott Morton F: Hospitals, market share, and consolidation. JAMA 310:1964-1970, 2013

15. Desai V, Gonda D, Ryan SL, Briceño V, Lam SK, Luerssen TG, et al: The effect of weekend and after-hours surgery on morbidity and mortality rates in pediatric neurosurgery patients. J Neurosurg Pediatr 16:726-731, 2015

16. Fendler W, Baranowska-Jazwiecka A, Hogendorf A, Walenciak L, Szadkowska A, Piotrowski A, et al: Weekend matters: Friday and Saturday admissions are associated with prolonged hospitalization of children. Clin Pediatr (Phila) 52:875-878, 2013

17. Freemantle N, Richardson M, Wood J, Ray D, Khosla S, Shahian D, et al: Weekend hospitalization and additional risk of death: an analysis of inpatient data. J R Soc Med 105:74-84, 2012

18. Goh KY, Lam CK, Poon WS: The impact of teleradiology on the inter-hospital transfer of neurosurgical patients. Br J Neurosurg 11:52-56, 1997

19. Goldstein SD, Papandria DJ, Aboagye J, Salazar JH, Van Arendonk K, Al-Omar K, et al: The "weekend effect" in pediatric surgery-increased mortality for children undergoing urgent surgery during the weekend. J Pediatr Surg 49:10871091,2014

20. Hixson ED, Davis S, Morris S, Harrison AM: Do weekends or evenings matter in a pediatric intensive care unit? Pediatr Crit Care Med 6:523-530, 2005

21. Holland CM, McClure EW, Howard BM, Samuels OB, Barrow DL: Interhospital transfer of neurosurgical patients to a high-volume tertiary care center: opportunities for improvement. Neurosurgery 77:200-207, 2015

22. Johnston SC: Effect of endovascular services and hospital volume on cerebral aneurysm treatment outcomes. Stroke 31:111-117, 2000

23. Laupland KB, Shahpori R, Kirkpatrick AW, Stelfox HT: Hospital mortality among adults admitted to and discharged from intensive care on weekends and evenings. J Crit Care 23:317-324, 2008

24. Lawton MT, Du R: Effect of the neurosurgeon's surgical experience on outcomes from intraoperative aneurysmal rupture. Neurosurgery 57:9-15, 2005

25. McLaughlin N, Laws ER, Oyesiku NM, Katznelson L, Kelly DF: Pituitary centers of excellence. Neurosurgery 71:916926, 2012

26. Mikulich O, Callaly E, Bennett K, O'Riordan D, Silke B: The increased mortality associated with a weekend emergency admission is due to increased illness severity and altered case-mix. Acute Med 10:182-187, 2011

27. Pollack MM, Patel KM, Ruttimann UE: PRISM III: an updated Pediatric Risk of Mortality score. Crit Care Med 24:743-752, 1996
28. Pollack MM, Ruttimann UE, Getson PR: Pediatric Risk of Mortality (PRISM) score. Crit Care Med 16:1110-1116, 1988

29. Powell EC, Atabaki SM, Wootton-Gorges S, Wisner D, Mahajan P, Glass T, et al: Isolated linear skull fractures in children with blunt head trauma. Pediatrics 135:e851-e857, 2015

30. Rollins MD, Barnhart DC, Greenberg RA, Scaife ER, Holsti $M$, Meyers RL, et al: Neurologically intact children with an isolated skull fracture may be safely discharged after brief observation. J Pediatr Surg 46:1342-1346, 2011

31. Salihu HM, Ibrahimou B, August EM, Dagne G: Risk of infant mortality with weekend versus weekday births: a population-based study. J Obstet Gynaecol Res 38:973-979, 2012

32. Samuels O, Webb A, Culler S, Martin K, Barrow D: Impact of a dedicated neurocritical care team in treating patients with aneurysmal subarachnoid hemorrhage. Neurocrit Care 14:334-340, 2011

33. Schneider EB, Hirani SA, Hambridge HL, Haut ER, Carlini AR, Castillo RC, et al: Beating the weekend trend: increased mortality in older adult traumatic brain injury (TBI) patients admitted on weekends. J Surg Res 177:295-300, 2012

34. Task Force for Children's Surgical Care: Optimal resources for children's surgical care in the United States. J Am Coll Surg 218:479-487, 487.e1-487.e4, 2014

35. Tung YC, Chang GM, Chen YH: Associations of physician volume and weekend admissions with ischemic stroke outcome in Taiwan: a nationwide population-based study. Med Care 47:1018-1025, 2009

36. Uren B, Lowell MJ, Silbergleit R: Critical care transport of patients who have acute neurological emergencies. Emerg Med Clin North Am 27:17-26, vii, 2009

37. Walcott BP, Coumans JV, Mian MK, Nahed BV, Kahle KT: Interfacility helicopter ambulance transport of neurosurgical patients: observations, utilization, and outcomes from a quaternary level care hospital. PLoS One 6:e26216, 2011

38. Worni M, Schudel IM, Østbye T, Shah A, Khare A, Pietrobon R, et al: Worse outcomes in patients undergoing urgent surgery for left-sided diverticulitis admitted on weekends vs weekdays: a population-based study of 31832 patients. Arch Surg 147:649-655, 2012

39. Youn YH, Park YJ, Kim JH, Jeon TJ, Cho JH, Park H: Weekend and nighttime effect on the prognosis of peptic ulcer bleeding. World J Gastroenterol 18:3578-3584, 2012

\section{Disclosures}

The authors report no conflict of interest concerning the materials or methods used in this study or the findings specified in this paper.

\section{Author Contributions}

Conception and design: Jea, Hansen, Briceño, Moreno, Ryan. Acquisition of data: Vedantam, Hansen, Briceño, Moreno, Ryan. Analysis and interpretation of data: Vedantam, Hansen, Briceño, Moreno, Ryan. Drafting the article: all authors. Critically revising the article: Jea, Hansen, Briceño, Moreno, Ryan. Reviewed submitted version of manuscript: all authors. Approved the final version of the manuscript on behalf of all authors: Jea. Study supervision: Jea.

\section{Correspondence}

Andrew Jea, Division of Pediatric Neurosurgery, Goodman Campbell Brain and Spine, Riley Hospital for Children, 705 Riley Hospital Dr., Indianapolis, IN 46202. email: ajea@ goodmancampbell.com. 